\title{
Research on Perceived Image of Historical and Cultural District Based on Grounded Theory_-Take Dashilan as an example
}

\author{
WANG Kun \\ School of Economics and Management, Beijing Jiaotong University, Beijing, China
}

\begin{abstract}
This article collects tourists' online comments on Ctrip.com, a historical and cultural block in Dashilan, Beijing. Based on grounded theory and text content analysis tool ROST.CM6, it analyzes the perception image of tourists in historical and cultural blocks. Positive perception factors include tourism resources, tourism environment, reception, and traffic location. Negative perception factors can be divided into three aspects: tourism soft environment, reception, and tourism product. Corresponding improvement suggestions are proposed for tourists' negative perceptions.
\end{abstract}

\section{$1 \quad$ Literature review}

The perception of tourism image not only affects tourists' decision-making, but it is also very important for the promotion of tourism destinations. The research on tourism perception image began with Hunt's doctoral dissertation in 1971[1], and the concept of tourism destination image was first proposed by Mayo in1973[2]. Studies by Boulding[3], Woodside[4], Chon[5], Gartner[6] and others have found the important role of tourism perception image in tourism decision making, and research on tourism perception image has become a hot spot. Regarding the research on the connotation of tourism perception image, Baloglu and McCleary proposed that the cognitive image and emotional image together constitute the overall image [7].Foreign scholars have further studied the influencing factors of tourist perception image. Mayo believes that the scenery, climate and traffic of tourist destinations affect the perception image[2], Beerli and Martin believe that information sources have an important effect[8], and Baloglu believes that stimulus factors and individuals The psychological and social factors formed the destination image[9].Reseach on the formation process of tourist perception image, Gunn proposed that the formation of tourist destination image can be divided into original image (organic image) and induced image[10]. Fakeye and Crompton extended the complex image (complex image) on this basis) Concept[11].

Foreign countries have also explored the marketing management of tourism perception images. Sheth et al. Established a market selection and consumption model for tourism perception images[12].Other scholars also emphasized the need to propagate through multiple visual images to highlight the uniqueness and differences of tourist destinations.
Li Leilei's "Tourism Image Planning: Theory and Practice" is China's first monograph on systematically exploring tourism imagery[13]. On the basis of absorbing foreign theories, she also introduces the hierarchy and geographical differentiation of geography It is applied to the study of the process and law of tourist destination image formation[14].Studies on the factors affecting tourism perception have gradually increased. Song Zhanghai analyzed the relationship between tourist attraction factors, cultural factors and related ancillary factors and the perceived image of tourists[15].And statistical research, the influence degree of various factors is ranked[16]. Cheng Ye and Sui Lina proposed a conceptual model of tourism perception based on the relationship between stimulus, individual factors and perceived image[17].Yao Changhong et al. Constructed a hierarchical evaluation model of perception bias based on the image subject and perceived content[18].The shaping and dissemination has important guiding significance. These studies have provided conditions for the marketing management of tourism image.Li Jie put forward targeted marketing strategies for the formation of tourist destination image[19].On the basis of fully explaining the importance of tourist destination image, Guo Lufang proposed the development of tourist destination image marketing strategy. Issues that should be paid attention to in the process are the image theme, image promotion, image shaping, and image enhancement[20].

The research results of tourism perception image are quite rich. Chinese and western blend, interdisciplinary, multi-methods and mutual promotion. However, there are few researches on tourism perception image in historical and cultural blocks. The study of the perceived image of historical and cultural blocks can reflect the quality of tourists' experience in renovating and updating the blocks, which is of great significance to the development and management of tourist destinations such as historical and cultural blocks. This article takes 
the first batch of historical and cultural districts in Beijing as an example. Based on the online reviews of mainstream tourism websites, based on grounded theory and analysis using text content analysis software (ROST.CM6),it builds a perceived image of historical and cultural districts in order to promote historical culture. The overall protection of the neighborhood and the local economic development provide some theoretical contributions.

\section{Study design}

\subsection{Case selection and data collection}

Dashilan is the first batch of historical and cultural districts, and it is also a well-known commercial street in Beijing. It is located in the center of old Beijing, south of Tiananmen Square and west of Qianmen Street. It is an important part of the south central axis. It has a history of more than 500 years. It emerged in the Yuan Dynasty and built wooden fences for social security since the Ming Dynasty. The fence is extraordinarily large, so it is called the dazha fence. Dashilan is an old commercial street with a history of hundreds of years. Eight wellknown old brands are opened here, as well as five big theaters in history. It has been renovated three times since the 1960s for cultural relic restoration, protection and repair, style decoration, and renovation. The building has an antique appearance, which maximizes the restoration and display of the traditional commercial features of Dashilan.

This article collects data samples by collecting Ctrip.com. As of February 1, 2020, there were a total of 850 tourist reviews, of which 496 were very well, 243 were good, 75 were average, 16 were bad, 10 were very poor, and the praise rate was good. The overall score is 4.4 points. Excluding invalid data in reviews, including content that is too short, repetitive reviews, irrelevant to the case, and advertisement-like reviews. After screening, 765 valid reviews were used as data for this study. The review time is from 2014 to the present.

\subsection{Research methods and steps}

Grounded theory is a qualitative research method proposed by American scholars Glaser and Strauss in the 1960s[21], and its core content is refining categories. By progressively encoding the original data, it is continuously summarized until the theory is saturated. The programmatic and rooted theoretical method proposed by Strass, that is, following the three steps of open coding, spindle coding and selective coding, is the most commonly used coding process. As one of the most commonly used methods in the social sciences, its application in the tourism industry has also increased in recent years.

\section{Analysis of Tourists' Perception of Dashilan}

\subsection{Analysis of Tourists' Positive Perception of Dashilan}

The high-frequency words were extracted with the software ROST.CM6 based on the online review text, and analyzed and summarized. It was found that tourists' perception of Dashilan mainly includes five dimensions: tourism resources, tourism environment, reception, traffic location, and Overall Recognition. Among them, the most evaluated are tourism resources, accounting for $40.3 \%$, followed by transportation location, and the tourism environment, accounting for $25.6 \%$ and $22.7 \%$, respectively, and the smallest are comments on the reception service category, which is also negative. The one with the most comments. On the whole, there are more positive perceptions than negative perceptions, indicating that tourists are more positive about Dashilan, a historical and cultural block.

TABLE 1 Comments on the classification and proportion of high-frequency words

\begin{tabular}{|c|c|}
\hline $\begin{array}{l}\text { Main category } \\
\text { (word } \\
\text { frequency / }\end{array}$ & $\begin{array}{l}\text { High frequency } \\
\text { words(frequency) }\end{array}$ \\
\hline $\begin{array}{l}\text { tourism } \\
\text { resources } \\
\qquad(1552 / 40.3 \%)\end{array}$ & $\begin{array}{l}\text { Time-honored (224) Specialty } \\
\text { snacks (124) Old shops (99) } \\
\text { Shops (106) History (68) Beijing } \\
\text { specialty products (63) } \\
\text { Architecture (59) Quanjude (53) } \\
\text { Taste (50) Tongrentang (48) } \\
\text { Culture (47) Ruixian Xiang (39) } \\
\text { Roast Duck (37) Ancient (35) } \\
\text { Tradition (30) Dong Lai Shun } \\
\text { (29) Inline Sheng (28) Zhang } \\
\text { Yiyuan (26) Fried Noodle (26) } \\
\text { Shopping (23) Reservation (23) } \\
\text { Liubiju (23) Beijing style (23) } \\
\text { Deyunshe (21) Brand (20) } \\
\text { Goubuli (17) Shoes (16) } \\
\text { Commodities (15) Marinated (14) } \\
\text { Daguanlou (13) Folk Customs } \\
\text { (13) Republic of China (13) Burst } \\
\text { (12) ) Taking photos (12) Trams } \\
\text { (12) Daoxiang Village (11) } \\
\text { Scenery (11) Night scenes (10) } \\
\text { Buns (10) Pickles (10) Wu Yutai } \\
\text { (9) Crosstalk (9) Silk (8) } \\
\text { Cantaloupe (8) Wax Museum (8) } \\
\text { Satin (7) }\end{array}$ \\
\hline $\begin{array}{l}\text { tourism } \\
\text { environment } \\
\qquad(881 / 22.7 \%)\end{array}$ & $\begin{array}{l}\text { Commercial Street (144) Alleys } \\
\text { (110) Alleys (95) Commercial } \\
\text { (62) Lively (58) Prosperous (51) } \\
\text { Tourists (40) Pedestrian Street } \\
\text { (35) Antique (32) Old Street (29) } \\
\text { Breath (23) Remodeling the } \\
\text { Atmosphere (22) Beijingers (22) }\end{array}$ \\
\hline
\end{tabular}




\begin{tabular}{|c|l|}
\hline & $\begin{array}{l}\text { Renovation (19) Business District } \\
\text { (17) Style (15) Environment (14) } \\
\text { Block (13) Food Street (12) Clean } \\
\text { (12) Commercialization (12) } \\
\text { Beautiful (11) Lined Up (9) Snack } \\
\text { Street (8) }\end{array}$ \\
\hline $\begin{array}{c}\text { reception } \\
(172 / 4.4 \%)\end{array}$ & $\begin{array}{l}\text { Expensive (87) Price (27) Cheap } \\
\text { (21) Hotel (20) Line up (9)Waiter } \\
\text { (8) }\end{array}$ \\
\hline & Beijing (601) Qianmen (183) \\
& Tiananmen (74) Shopping (51) \\
Walking (30) Wangfujing (18) \\
traffic location & Xianyukou (18) Around (17) \\
$(993 / 25.6 \%)$ & Central Section (16) South \\
& Central Axis (11) Food Street \\
& (10) Forbidden City (8) \\
& Downtown (7) \\
\hline \multirow{5}{*}{ overall } & Like (60) Recommend (37) \\
Recognition & Famous (33) Feel (32) Delicious \\
(279/7.2\%) & (31) Experience (20) Interesting \\
& (16) Authentic (15) Fun (11) \\
& Can't miss (10) Fair (7) \\
Unpalatable (7)
\end{tabular}

"Tourism resources" is the first major positive perception factor for tourists. It is summarized according to the grounded theory. It is mainly divided into three categories: material relics, cultural connotations, and activity items. For example, the "old name" such as "Quanjude", "Ruifuxiang" is very high, and they also appreciate the architectural style of the Republic of China. These belong to the category of "material relics". The "cultural connotation" in tourist comments is mainly reflected in the emphasis on Dashilan's 500-year history and the origin of the name.There are various special activities and entertainment methods in the Dashilan neighbourhood to meet the various needs of tourists such as eating, drinking and playing.

"Traffic location" is the second largest positive perception factor for tourists to Dashilan. According to the grounded theory, it can be summarized from two aspects, one is tourist traffic and the other is tourist location. Dashilan occupies an excellent location in the center of Beijing. The convenient public transportation in the capital brings a large number of tourists to Dashilan. It is close to the famous traditional tourist attractions such as the Forbidden City, Tiananmen, and Temple of Heaven. Foreign tourists choose to stop by here, Experience the old Beijing culture.

The tourist environment is the third largest positive perception factor of Dashilan. After the renovation of Dashilan, the original dirty and messy phenomenon was changed, and it became orderly, clean and tidy, providing tourists with a comfortable travel experience. The street is not long, the layout is simple, the atmosphere is lively, and it is very prosperous. It can be completed in ten minutes. Therefore, after comparison, tourists think that the environment and space of Dashilan are suitable for play. The soft environment was mainly about the performance of the local residents and the market environment.
"Reception" is the fourth most positive perception factor for tourists. The analysis is mainly from two aspects: service level and reception facilities. The content of the reception facilities in the comments is relatively small, but it also involves general infrastructure and service facilities, such as tourist toilets and hotels, and most of them give positive reviews. But for the service level item, it contains more negative comments and will be further analyzed in the negative perception factors.

\subsection{Analysis of tourists' negative perception of Dashilan}

Among the 765 pieces of data, there are 50 negative comments after statistics. These negative comments represent the tourists' negative perception of Dashilan. They should be systematically analyzed and targeted for improvement. Still using the ROST.CM6 to extract highfrequency words, and refine the core categories according to the programmatic coding method, which are summarized into three categories.

Dashilan's historical and cultural districts are concentrated in the three aspects of tourism soft environment, reception, and tourism products. Among them, the proportion of reception is the largest, reaching $35.9 \%$. The quality of the reception service directly affects the tourist's mood, especially in terms of service level, the waiter has a bad attitude, a bad temper, a lack of service awareness, a high price, and the phenomenon of slaughtering foreign tourists affects the image of tourist destinations. Secondly, in terms of tourism products, the century-old shop is an important tourist attraction in the historical and cultural district of Dashilan. However, due to its attributes and tourist souvenirs. Quanjude, Duyichu and other old shops are facing the evaluation that "the taste has changed and it is not delicious". Other tourist shops and products are not high-grade, such as imitations of cottages. Finally, in terms of the soft tourism environment, although the planned and reconstructed Dashilan fence is clean and tidy, many tourists think that the previous feeling is missing. The local customs are relatively thin, the degree of commercialization is too high, and the regional culture displays is not obvious, and it is no different from other famous streets such as Jinli in Chengdu and Huimin Street in Xi'an. On the other hand, the business environment is poor and has encountered scams or routine tourists. This has led to a decline in the quality of the experience of some tourists.

TABLE 2 Negative comment high-frequency word encoding

\begin{tabular}{|l|l|l|}
\hline $\begin{array}{l}\text { Selective } \\
\text { coding } \\
\text { (word } \\
\text { frequency / } \\
\text { percentage) }\end{array}$ & $\begin{array}{l}\text { Spindle coding (word } \\
\text { frequency / percent) }\end{array}$ & $\begin{array}{l}\text { High } \\
\text { frequency } \\
\text { words } \\
\text { (frequency) }\end{array}$ \\
\hline $\begin{array}{l}\text { tourism soft } \\
\text { environment } \\
(36 / 31.6 \%)\end{array}$ & $\begin{array}{l}\text { business environment } \\
(24 / 21.1 \%)\end{array}$ & $\begin{array}{l}\text { Business (9) } \\
\text { Scam (6) } \\
\text { Outsider (6) }\end{array}$ \\
\hline
\end{tabular}




\begin{tabular}{|c|c|c|}
\hline & & Beijinger (3) \\
\hline & $\begin{array}{l}\text { environment } \\
\text { atmosphere((12/10.5\%) }\end{array}$ & $\begin{array}{l}\text { No style (3) } \\
\text { Remodeling } \\
\text { (3)Messing } \\
\text { (2) History } \\
\text { (2) } \\
\text { Nondescript } \\
\text { (1) } \\
\text { congestion } \\
\text { (1) }\end{array}$ \\
\hline \multirow[b]{2}{*}{$\begin{array}{l}\text { reception } \\
(40 / 35.9 \%)\end{array}$} & $\begin{array}{l}\text { accommodation } \\
\text { facilities }(3 / 2.6 \%)\end{array}$ & $\begin{array}{l}\text { Inn (2) Hotel } \\
\text { (1) }\end{array}$ \\
\hline & $\begin{array}{l}\text { service level } \\
(38 / 33.3 \%)\end{array}$ & $\begin{array}{l}\text { Price (9) } \\
\text { Commercial } \\
\text { (9) Waiter } \\
\text { (6) Temper } \\
\text { (5) Value for } \\
\text { money (3) } \\
\text { Driver (2) } \\
\text { Weighing (2) } \\
\text { Packaging } \\
\text { bag (2) }\end{array}$ \\
\hline $\begin{array}{l}\text { tourism } \\
\text { product } \\
\text { (37/32.5\%) }\end{array}$ & $\begin{array}{l}\text { tourism product } \\
(37 / 32.5 \%)\end{array}$ & $\begin{array}{l}\text { Old shop } \\
\text { (12) Shop (4) } \\
\text { Taste (7) } \\
\text { Souvenirs } \\
\text { (4) } \\
\text { Unpalatable } \\
\text { (3) } \\
\text { Commodities } \\
\text { (2) Items (2) } \\
\text { Cottages (1) } \\
\text { Not } \\
\text { necessary (1) } \\
\text { Grade (1) }\end{array}$ \\
\hline
\end{tabular}

\subsection{Tourists' overall perception of the image of Dashilan}

Tourists often give overall evaluation after commenting, and based on the analysis of online texts, the tourists' overall perception of Dashilan's historical and cultural districts is summarized, including two aspects: perception attitude and overall evaluation. Positive reviews occupy most of the tourists. Tourists expressed "like" and "recommended" tourist tours, and found them "interesting," fun ", and" cannot miss ".At the same time, we also found that tourists are still on sightseeing tours of Dashilan historical and cultural districts In the stage, it is more used as a time-honored sightseeing spot in China, a punching place in famous national scenic spots, and a tasting place for Beijing snacks. The perception image of Dashilan is biased towards the internet-famous site, gourmet experience, and historical style. There is less attention to the historical stories and cultural connotations behind the cultural block, and it is impossible to deeply appreciate its humanistic charm.

\section{Conclusions and recommendations}

\subsection{Conclusion}

This article uses Beijing 's Dashilan historical and cultural district as an example. It uses Ctrip 's travel reviews to obtain raw data, and uses grounded theory and text analysis methods to study tourists 'perception of historical and cultural districts. It systematically extracts tourists' positive perceptions and negative factors. Perceived factors, the following conclusions are drawn:

\subsubsection{Tourists 'positive perception of historical} and cultural blocks mainly includes four aspects: tourism resources, tourism environment, reception, and traffic location; tourists' negative perceptions of historical and cultural blocks are mainly concentrated in tourism soft environment, reception and tourism product.

\subsubsection{The overall perception image of tourists to} the historical and cultural block of Dashilan: internetfamous site with gastronomic experience and historical features, reflecting the existence of traditional cultural relics in historical and cultural blocks that cannot be fully maintained and cultural connotations not deepened The lack of creativity in tourism products and the lack of historical humanities experience will be the main direction for the promotion of historical and cultural districts in the future.

\section{2 recommendations}

Aiming at tourists 'negative perception of Dashilan, this article proposes the following improvement measures, in order to provide some reference for the improvement of tourists' perception image in historical and cultural blocks.

\subsubsection{Pay attention to the protection of style and features, and tap the cultural connotation}

Historical and cultural districts must not only protect the cultural relics and historic buildings and historic buildings that constitute historical features, but also preserve all the elements that make up the overall style. The Dashilan block has retained the pattern of "three vertical and nine horizontal" from the end of Ming Dynasty to the beginning of Qing Dynasty, which is a material object of key protection. At the same time, we must explore the stories behind historical and cultural blocks, use multiple channels and methods to dynamically display the historical origins, celebrities, business features, and other connotations. Visit and experience the production process of time-honored products, creative collection activities of time-honored products, and exhibitions of time-honored merchants. Project to increase tourist experience 


\subsubsection{Improve product quality and curb excessive commercialization}

The control of businesses and goods in the neighborhood highlights the cultural characteristics of Beijing's old city. It should make reasonable layout of commercial areas, avoid homogeneous shops and products, and curb excessive commercialization. Demolition of buildings and facilities that hinder the style and landscape of the block, or uniform regulations. Rectify business signs to avoid visual clutter. In addition to sightseeing and shopping, increase experiential activities or projects, and actively organize various historical and cultural events or performances to highlight the image of the neighborhood.

\subsubsection{Standardize market order and improve service level}

To strengthen the management of the soft market environment in historical and cultural districts, the first is to investigate and deal with "business scam behaviors" reflected by tourists, regulate market order, and avoid such behaviors. The second is the introduction of professional talents, focusing on those with historical and cultural protection and development experience. We must also actively train existing personnel to improve the reception service level of service personnel in the neighborhood, increase channels for complaints and reports, and listen to tourist suggestions.

\subsubsection{Maintain community traditions and improve living environment}

The historical and cultural block is a large area with a large number of residents living there. It is a living cultural heritage and has its own unique community culture. It should maintain community traditions, respect the social needs of residents, and improve the living environment of residents in the block. Ensuring communities receive corresponding economic, spiritual or material compensation, encouraging residents to actively participate in tourism activities, and promoting regional economic vitality.

This study only selects the Dashilan historical and cultural block as the research object, whether the case selection and tourist data can reflect the tourists' perception of the overall situation of the historical and cultural block remains to be tested with comparative cases and field surveys. At the same time, the perception of domestic and foreign tourists is compared. Comparative studies of different groups, such as the perception of community stakeholders, are future directions for discussion.

\section{References}

1. Hunt J D. Image as a factor in tourism development. Journal of Travel Research, 1975, 13(3): 1-7.

2. Mayo E J. Regional images and regional travel behavior[A].In: The fourth annual conferenceproceedings of the Travel Research
Association Researeh for Changing Travel Patterns: Interpretation and Utilization[C] .August 1215,1973,211-218.

3. Boulding, K. The Image. Ann Arbor:University of Michigan Press[M]. 1956.

4. Woodside, A. G., and S. Lysonski. A General Model of Traveler Destination Choice[J].Journal of Travel Research, 1989, 16 (winter): 8-14.

5. Chon, K. S. The Role of Destination Image in Tourism: A Review and Discussion[J].The Tourist Review, 1990,2: 2-9.

6. Gartner, C. M. The Meaning and Measurement of Destination Image [J].Journal of Tourism Studies, 1991, 2 (2): 2-12.

7. Baloglu S, McCleary KW.A model of destination image formation[J]. Annals of Tourism Research, 1999, 26 (4) : 868-897.

8. Beerli A, Martín J D. Factors Infl uencing Destination Image[J]. Annals of Tourism Research, 2004, 31(3): 657-681.

9. Baloglu,S.The Relationship between Destination Images and Socio- demographic and Trip Characteristics of International Travelers [J]. Journal of Vacation Marketing,1997,3:221-233.

10. Gunn CA.Vacationscape:Designing tourist regions[M].Austin:Bureau of Business Research, University of Texas, 1988.

11. Fakeye PC, Crompton JL.Image difference between prospective, first-time and repeat visitors to the lower Rio Grande Valley[J].Journal of Travel Research, 1991,30 (2) : 10-16.

12. Sheth, J. N., B. I. Newman, and B. L.Gross. Consumption Val-ues and Market Choices[M]. Cincinnati, OH: South- Western.1991.

13. Li Leilei. Tourism destination image planning: theory and practice [M]. Guangzhou: Guangdong Tourism Press, 1999.

14. Li Leilei. Spatial cognition process and regularity of tourism destination image $[\mathrm{J}]$. Geography Science, 2000, (12): 565-568.

15. Song Zhanghai. Discussion on the image of tourist destinations from the perspective of tourists [J]. Tourism Tribune, 2000, (1): 63-67.

16. Li Feng . Research on the Elements Constituting Pre-Tourist Perceived Image of Ancient Towns [J]. Soft Science, 2008, (5): 23-28.

17. Cheng Yi, Sui Lina. Research on Tourist Perceived Image Model and Its Application-Taking Residents in the Yangtze River Delta An Example of Perceived Image of Tourism in South Korea [J]. Tourism Science, 2007, (2): 7-12.

18. Yao Changhong, Chen Tian, Liu Jiaming. Study on Evaluation Model of Perceived Image Deviation in Tourist Destinations [J] .Journal of Tourism, 2009, (1): 29-32. 
19. Li Jie. On Tourism Destination Image and Its Marketing Significance [J]. Tourism Forum, 1998, (1): $15-18$.

20. Guo Lufang. China's Implementation of Tourism A Preliminary Study of Land Image Marketing Strategies [J] .Tourism Science, 1999, (2): 34-35.
21. Wang Xiaoling.Research on Influencing Factors of Customer Relationship Management in HR Department Based on Grounded Theory [J] .Soft Science, 2013,27 (06): 98-102 + 113 . 